\title{
The Privileging of English Language Use in Academia: Critical Reflections from an International Doctoral Seminar
}

\section{El privilegiado uso del inglés en la academia: reflexiones críticas desde un seminario internacional de doctorado}

\author{
Jon Woodend \\ University of Calgary \\ jdwooden@ucalgary.ca \\ Canada \\ Sylvie Roy ${ }^{1}$ \\ University of Calgary \\ syroy@ucalgary.ca \\ Canada
}

\author{
Lisa Fedoruk \\ University of Calgary \\ lisa.fedoruk@ucalgary.ca \\ Canada \\ Xueqin Xu \\ University of Calgary \\ xuwu@ucalgary.ca \\ Canada
}

\author{
Avis Beek \\ University of Calgary \\ abeek@isp.cz \\ Canada \\ Janet Groen \\ University of Calgary \\ jgroen@ucalgary.ca \\ Canada \\ Xiang Li \\ University of Calgary \\ xiangli@nait.ca \\ Canada
}

\begin{abstract}
:
In this article, we, a Canadian team of doctoral researchers, reflected on our journey during an International Doctoral Research Seminar (IDRS) held in Beijing in 2015. As five doctoral students and two academics, we met with our doctoral colleagues from academic institutions in Brisbane (Australia) and Beijing (China). Although we did not discuss or negotiate which language we would be using in China, we were confronted with our assumption that we would communicate in English. It was apparent that this assumption of English language use privileged some (i.e., Canadian and Australian teams) while disadvantaging others whose first language was not English (i.e., Chinese team). From this confrontation arose questions and concerns about equity in participation. As a result, this unique case study chronicles the Canadian team reflecting on the IDRS experience including our privilege of using English, resulting in a more inclusive space for all future participants to engage equitably in this international collaboration. We used a transcultural and transidiomatic framework from Pennycook (2007) that guided our reflections. Through discourse analysis, we were able to make meaning of our reflections, resulting in the necessity to address the domination of English as a lingua franca in academic spaces and facilitate an inclusive transcultural space for all participants.
\end{abstract}

Keywords: Transcultural space, Transidiomatic practices, English as lingua franca, Ideologies, International doctoral seminar.

\section{Resumen:}

En este artículo, nosotros, un equipo canadiense de investigadores a nivel de doctorado, reflexionamos sobre nuestra experiencia durante el desarrollo de un Seminario Internacional de Investigación Doctoral implementado en Beijing en 2015. Cinco estudiantes de doctorado y dos académicos, nos reunimos con nuestros colegas de doctorado de instituciones académicas en Brisbane (Australia) y Beijing (China). Aunque no discutimos ni negociamos qué idioma utilizaríamos en China, nos encontramos con que el idioma asumido de comunicación debía ser el inglés. Era evidente que esta suposición del uso del inglés privilegiaba a algunos (es decir, a los equipos de canadienses y australianos) mientras que perjudicaba a otros (es decir, al equipo chino). De este conflicto surgieron preguntas e inquietudes sobre la equidad en la participación. Utilizamos un marco transcultural y transidiomático de Pennycook (2007) que guió nuestras reflexiones. A través del análisis del discurso, pudimos dar sentido a nuestras reflexiones, lo que resultó en la necesidad de abordar el dominio del inglés como lingua franca en los espacios académicos y facilitar un espacio intercultural inclusivo para todos los participantes.

Palabras clave: Prácticas y espacio transculturales y transidiomáticas, inglés como lengua franca, ideologías, seminario internacional de doctorado.

Received: 13/02/2019 | Accepted: 22/07/2019 | Published: 30/09/2019

| Pp. 1 - 22 
The Privileging of English Language Use in Academia: Critical Reflections from an International Doctoral Seminar

\section{Introduction}

In this globalized society, English is often considered an international language, particularly within influential fields such as business, c om munication/t e chnology, medicine, and the sciences (Gil, 2011). English as lingua franca means that the use of this language in the world is not typically questioned or reflected upon and seems 'natural', which Kroskrity (2010) called an ideology. An ideology is often the product of a historical past that is taken for granted. In that sense, the spread of English worldwide can be attributed to two major historical mechanisms (Graddol, 1997). The first was Britain's colonial expansion from the late 16 th century to the early 20th century. The British colonizers imposed English as the official language in their territories across the globe even though many of the indigenous peoples continued to use their native languages. The second historical event entailed the rise of the United States as an economic power country later in the 20th century. English continued to spread worldwide with the political, economic, and cultural expansion of the United States, a global superpower. Phillipson (2009: 30) called the expansion of English under the force of colonialism and neocolonialism "linguistic imperialism" due to its use to serve the interests of specific groups, often to the detriment of others. In other words, English was "a big commodity" (Phillipson, 2009: 30) and the expansion of this language brought political and economic benefits to countries like the United Kingdom and the United States. Relatedly, the World Englishes' model from Krachu (1997) also explained the domination of the Inner Circle (i.e., United Kingdom, United States, Canada and Australia) which dictated which English variety should be spoken in different regions 
The Privileging of English Language Use in Academia: Critical Reflections from an International Doctoral Seminar

of the world in order to gain access to economical resources.

From this view, difficulties communicating and disseminating work in English can impede individual, organizational, and even national success. As such, for decades, English has been the language of choice in education in non-English speaking countries (i.e., the Expanding Circle, Krachu, 1997) in order to prepare the subsequent generations for success in this global market (Chang, 2011; Guo, 2012). When one language is privileged over others, it inherently controls who has access to opportunities, and those who are able to assimilate to this privileged language can often receive systemic rewards that further perpetuate this privilege and create normalized ways of being (Jacquemet, 2005; Stein \& de Andreotti, 2016).

Only through reflection and questioning of these accepted takenfor-granted practices can space be created to invite other ways of being (Fedoruk, Woodend, Groen, Beek, Roy, $\mathrm{Wu}, \& \mathrm{Li}, 2018)$. It is important to recognize how English is used in a complex world, how English is involved in global flows of culture and knowledge, and how it is used around the world and for what consequences for local populations (Pennycook, 2007). This invitation of reflection is critical when discussing who has access to or is being denied education through assumptive behavior, as well as how this accessibility influences the outcomes of education (e.g., creativity, innovation) for individuals as well as for society. Ideally, academic gatherings are spaces to educate and learn in order to spark ingenuity and enhance societal well-being. If English is the lingua franca and access to these spaces is limited to those who are native speakers or those who excel in the English language, then it is concerning to think about the perspectives, information, skills, and expertise that are unheard and underutilized in addressing global concerns (Stein \& de Andreotti, 2016). Continuous exploration into these accepted ways of being in academic spaces is needed to highlight avenues for expanding participation. This is the issue addressed in this article, through critical accounts of participation in an international research collaboration. 


\section{|Background to the Study}

\section{International Doctoral Research Seminar: A Transnational Collaboration}

In this article, we, the authors, present our experiences and understanding of language as we used it during the International Doctoral Research Seminar (IDRS) held in Beijing in 2015 and how we could have been more inclusive. The IDRS is a collaborative initiative between the faculties of Education at Beijing Normal University (BNU) in China, Queensland University of Technology (QUT) in Australia, and the University of Calgary (U of C) in Canada. It is a joint annual International Doctoral Research Seminar hosted by partner universities in alternate years. In particular, the IDRS includes participation in collaborative, interdisciplinary, transcultural, and scholarly writing activities with student research presentations for a period of seven days, largely in English. For our group from the U of $\mathrm{C}$, the IDRS experience extended beyond the seven days in China. Specifically, the IDRS involved three stages: the pre-IDRS preparation, the IDRS in Beijing, and the postIDRS reflection and writing. In the pre-IDRS preparation, we discussed our understanding of cultural practices when visiting another country in addition to reading chapters and articles relevant to our upcoming trip (e.g., Luke, 2008; Guo \& Guo, 2016). We were five students pursuing doctoral degrees and two faculty members at the $\mathrm{U}$ of $\mathrm{C}$.

An exploration into our experiences of and reflections on language use in the IDRS was important for two key reasons. First, this was the primary year in which participants from the $U$ of $\mathrm{C}$ were invited to join the IDRS, which previously had existed as a collaboration between BNU and QUT (Mu, Zhang, Cheng, Fang, Li, Wang \& Dooley, 2019). As such, we approached this experience with curiosity, novelty, uncertainty, and few preconceived notions of what the IDRS ought to look like. Second, we were the only group amongst the three partner universities to include a combination of participants from different linguistic backgrounds. The QUT group consisted of English language speakers. The BNU group involved Mandarin speakers who 
The Privileging of English Language Use in Academia: Critical Reflections from an International Doctoral Seminar

used English as a second language. The U of C group was comprised of English language speakers, as well as Mandarin and French speakers with English as a second language. These perspectives provided for unique within-group discussions about the assumed use of English and who it privileged during the IDRS.

\section{Trans-Language and -Culture Framework}

Much of the World Englishes literature has focused on the nationalist point of view, meaning that research focuses on specific varieties in separate and local contexts (i.e., English in India, Korea, China; He \& Li, 2009; Ahn, 2014; Levis, Sonsaat \& Link, 2017). The use of Krachu's (1997) model of Inner Circle, Outer Circle, and the Expanded Circle is at the heart of trying to understand different English varieties in the world. The Inner Circle refers to the traditional, historical, and sociolinguistic bases of English as a first or native language of its population (e.g., United Kingdom, United States, Canada, Australia, etc.). The Inner Circle also involves the spread of English in the first diaspora when the British carried the language to its colonies. The Outer Circle is English language that was produced by the second diaspora when it spread to Asia and Africa. For example, in India and Tanzania, English is not the first language of the people, but it is used between language groups and for higher education, commerce, and other official means. Finally, the Expanding Circle includes the rest of the world where English has no historical connection and no governmental role in the country but is used for International communication. Usually, standard English is set by the Inner Circle, and the rest of the world seems to be dependent on how native speakers use the language.

Pennycook (2007) argued that the pluralization of English, as noted in the World Englishes framework, does not go far enough and pluralizes monolithic English, as it leaves out all other Englishes that do not fit the paradigm. Pennycook argued that post theories (i.e., postmodernism, postcolonialism) are outdated frameworks that serve to criticize 
rather than push limits and cross boundaries to shift perspective lenses. This author promotes 'trans' rather than 'post' theories because it opens up to processes of cultural interaction in terms of fluidity of relations across global contexts. The 'trans' notion is being recognized in the field of language and culture as a way to 'cross over' instead of looking at multilingualism and multiculturalism as being several separate languages and cultures. Other authors (e.g., Bhabha, 1994; Kramsch, 1999) proposed notions such as 'hybridity' or 'third place', not as one language or the other language, but as something newly emerging from the two. Then, transcultural and translingual competencies would be a concept of plurality or communication across and between cultures and communicative practices of transnational groups that interact using different languages and communicative codes. Pennycook (2007) argued for Global Englishes where:

The notions of transidiomatic and transcultural practices refer not merely to the spread of particular forms of culture across boundaries, not only to the existence of supercultural commonalities. They draw our attention instead to the constant processes of borrowing, bending and blending of cultures, to the communicative practices of people interacting across different linguistic and communicative code, borrowing, bending and blending languages into new modes of expression. (...) Transcultural and transidiomatic practices therefore refer not to homogenization or heterogenization but to alternative spaces of cultural production. (Pennycook, 2007: 47)

Pennycook explained how Global Englishes, which is the spread and use of English in the global world, should be looked at more critically, locating English within a more complex vision of globalization. One should look at English as a new form of power and control while looking at complex and new forms of resistance, change, and identity. Pennycook (2007) invited a focus on translocal and transcultural flows, 
The Privileging of English Language Use in Academia: Critical Reflections from an International Doctoral Seminar

a language of fluidity and to try to understand the effects of cultural flows; the use of English produces new forms of global identifications.

During the IDRS, we started with the preconception that everyone would use English because of the dominant ideology of it as a lingua franca. However, we slowly reflected on the opportunity for a trans-linguistic and -cultural space to be created while in Beijing.

\section{|Methodology}

\section{Doctoral Seminar Activities}

During our pre-departure, the $\mathrm{U}$ of $\mathrm{C}$ team met five times for a period of two hours to focus on creating group cohesion, as well as to engage in critical discussion about scholarship and resources related to international academic collaboration (e.g., Luke, 2008; Guo \& Guo, 2016). Outside of these meetings, we also had the tasks to read, comment, and post our reflections online in a learning management system. We also attended presentations by $\mathrm{U}$ of $\mathrm{C}$ faculty and staff knowledgeable in Chinese culture and customs. We had an intensive one week stay in Beijing along with colleagues from QUT. We attended preliminary presentations by the BNU faculty pertaining to The Chinese Education System, Minority and Gender Education in China, and Using Educational Technology in Chinese Schools. In addition, over two days, each graduate student from all participating institutions provided a presentation on their own research and engaged in social activities, such as cultural trips to the Great Wall of China and the Imperial Palace. Post-departure, the $\mathrm{U}$ of $\mathrm{C}$ team met multiple times to debrief our experience collaboratively. This full year of meeting and reflecting on our journey compelled us to continue the discourse on our experience, resulting in the focus of this article.

\section{Reflective Process: Case Study Method}

Before, during, and after the IDRS, we reflected on our experiences and collected our ideas and reflections in different ways. We knew that we would use these reflections for a subsequent article in order to offer some insights into our experiences, without knowing what specific topic 
or exploration the article would take. In this way, we fulfilled one of case study methodology's central criteria of intensive descriptions and analyses of a single unit or a bounded system, such as an individual, program, event, group, intervention, or community (Merriam \& Tisdell, 2016). More specifically, our reflections were part of an interpretive case study as Merriam and Tisdell (2016) described these particular studies as complex and multilayered, and particularly useful for their rich description and heuristic value, as the emphasis shifts to analyze data in order to interpret and theorize the phenomenon. The findings that emerged from our reflections are context specific to this particular IDRS and cannot be readily generalized. However, we stand by the logic of transferability of experience as proposed by Rossman and Rallis (2003: 105) when they stated that "reasoning by analogy - allows the application of lessons learned in one case to another population or set of circumstances believed or assumed to be sufficiently similar to the study sample that findings apply there as well.”
In the tradition of a case study approach (Merriam \& Tisdell, 2016), our study used a variety of techniques for data gathering. First, we wrote and shared predeparture reflective memos in the weeks leading up to the trip to China. These memos focused on imparting acceptable cultural and professional behavior in line with our partnering universities in an environment outside our Canadian context. Second, we kept field notes, photographs, and observations during the IDRS to understand the present moments of unfolding dynamics between the groups. Third, we engaged in shared reflective writing preceding the IDRS.

The main findings for this article occurred during the shared reflective writing post IDRS. This comprised the $\mathrm{U}$ of $\mathrm{C}$ team meeting after our experience in China to discuss observations and narrow our focus on particular shared topics. From these conversations, we realized we did not consider the assumption of English language use prior to and during the IDRS. In turn, as our discussion deepened to reflect on the notion of privilege 
The Privileging of English Language Use in Academia: Critical Reflections from an International Doctoral Seminar

surrounding language, we each engaged in individual reflections based on questions, such as "Why did we not consider language use pre-departure for IDRS?", "What did we realize about the privileging of a language as a result of IDRS?”, and 'What did we do about it?'. We reviewed our personal reflective memos, field notes, and observations then communally shared them in a Google Doc, which we jointly reflected on and appended. These personal and shared reflections constituted the data that informed this interpretive case study.

\section{Discourse Analysis}

In order to make sense of our data, we decided to use our questions to organize our thoughts. Using our own memos, field notes/ observations, and/or photographs, we individually answered the questions mentioned earlier. As a group, we reviewed and interpreted the individual answers to begin searching for common themes and ideas. To do this we used discourse analysis, which explains how language (i.e., our language or text or reflections) represents

meaning in specific socio-cultural, temporal, and historical contexts. We examined linguistic features and forms, as well as patterns and units constructed through texts beyond the single sentence level in order to make links between language and society (Gee, 2004; Cohen, Manion \& Morrison, 2018). As Gee (2004: 29) mentioned:

Context refers to an everwidening set of factors that accompany language in use (and thus is often used in the plural, contexts). These include the material setting, the people present (and what they know and believe), the language that comes before and after a given utterance, the social relationships of the people involved, and their ethnic, gendered, and sexual identities, as well as cultural, historical, and institutional factors. Most contemporary approaches to discourse analysis assume a reflexive view of the relationship between language and context. Reflexive here means that, at one and the same time, an utterance influences what we take the context to be, 
and context influences what we take the utterance to mean.

We used Gee’s (2014) practical guide to analyze our data to capture how language can perform different functions and build structures/ meanings in the world and how language contributes to building and rebuilding our worlds. Gee's notion of the Big "C" Conversation Tool helped us to ask what historical or social issues and discussions are assumed to be known by the readers/listeners and was our primary tool to understand how ideologies are represented in our own speech and why. Guided by Gee's (2014) communicative tools and language cues, we made sense of some of the ideologies related to English; these linked to participants' past experiences and understanding.

\section{Participant Profiles}

Given the personal nature of these reflections and in order to understand why a particular person states one particular thing, it is important to have a sense of our respective backgrounds, as they shape our perspectives. As such, we included short biographies of each of the $\mathrm{U}$ of $\mathrm{C}$ author-participants, starting with the two faculty mentors and then the five doctoral students.

JG is a native speaker of English, a faculty member, and is currently investigating transformative learning and spirituality in adult learning in varied contexts, such as higher education and adult environmental programs.

SR is a native speaker of French from Québec, a faculty member in the Language and Literacy specialization, and is currently investigating power and language ideologies in French immersion contexts.

$\mathrm{AB}$ is a Canadian native speaker of English who studied French in school and has acquired limited proficiency in other languages through her work in Nunavut and in international schools around the world. At the time of IDRS, she was an EdD candidate researching student international mindedness in International Baccalaureate students.

JW is a second-generation Canadian with dual citizenship with Britain, a native speaker of English, and 
learned French at school. JW worked in Japan as an English teacher and at the time of the IDRS, was a doctoral student in Counselling Psychology, exploring international students' university to work transitions.

LF is a native speaker of English who practiced Ukrainian, English, and French in her childhood home. She lived and worked in Japan as an English teacher and taught in Australia and Kazakhstan. At the time of the IDRS, LF was a doctoral student in Adult Learning who was focusing on the lived experiences of Chinese visiting scholars in Canada and the impact of these experiences on their teaching practices after returning to China.

$\mathrm{XW}$ is a native speaker of Mandarin who learned English and moved from China to Canada. Author XW was a doctoral candidate in Language and Literacy. She was investigating engagement in learning Mandarin as an additional language from an adult beginning learners' perspective.

Finally, XL is a native speaker of Mandarin who learned English and moved from China to Canada. Her research focused on the inter- subjectivity of cultures and values projected on Chinese students who are living in North America.

\section{|Discussion of Findings}

In this section, we presented some of the reflections of what it meant at the time and when we started to reflect on what happened pre-, during- and post- IDRS. Along with our reflections, we also provided a discussion to contextualize and offer potential explanations of them. We grouped these reflections according to two dominant topics, which emerged organically based on our research questions, including the Privileging of English as the Lingua Franca and Language Use as a Result of the International Doctoral Seminar.

\section{Reflections on the Privileging of English as the Lingua Franca}

To answer the first research question, "Why did we not consider language use predeparture for IDRS?”, we explored our experiences with English as a lingua franca more generally. English is often seen as the most efficient way to communicate with 
others. It is a strong ideology that exists in the world. The native English speakers that participated in this seminar recognized that the ubiquitous use/teaching of English in non-English speaking countries provided them with the benefit of communicating without speaking the local language when they travel. For example, JG recognized that as the native speaker of "the dominant language", it means "I have it very easy". The native English speakers discussed the phenomenon of English being "the language of privilege”. $\mathrm{AB}$, who teaches at overseas international schools, commented that typically only affluent families can afford to send their children to international schools, often to expose their children to native English teachers instead of non-native local teachers. This coincides with the ideology that native speakers are better brings about challenges for speakers of different English varieties (Kachru, 1997; Crystal, 2003). AB commented that "in general, in places where English is not the native language, it has become the language of privilege”. Furthermore, based on her experience of living and working in non-English speaking countries, author LF warned of the danger of the perspective that it is the nonEnglish speakers' responsibility to adapt and make themselves understood by native English speakers. She commented:

When it is your native language, and it is considered "the" global language, it can often be taken for granted that non-English speakers must adapt. This perspective can be dangerous as it contains layers that may manifest themselves in factors, such as power, privilege, entitlement, and superiority. What may get lost are the abilities to demonstrate empathy and compassion, to compromise and accommodate, which are essential for clear comprehension and positive growth as individuals and within the larger group.

Author JG, whose family was originally from Holland, expressed the regret of losing her heritage language in just one generation as a result of English as the lingua franca ideology:

Over the years, I constantly asked my parents why we as 
The Privileging of English Language Use in Academia: Critical Reflections from an International Doctoral Seminar

kids, never learned to speak Dutch. They indicated that they wanted to and needed to improve their English as quickly as possible - for jobs and everyday life. I suppose that made sense, but I did feel a real loss, as in just one generation, I had lost the language of my heritage.

We can see that the native speakers of English in this group reflected on their own privilege of using English. Their perceptions of English being 'the' global language, the 'dominant' language, and the language of privilege is prominent. Their reflective experiences teaching overseas make them aware of the power that they possess. However, they were raised with the idea that English was the language of success even if one of them lost her heritage language. English as a value market of cultural and symbolic capital (Bourdieu, 1986) is constructed as an ideology (i.e., cues are found in the excerpts: dominant, privilege, global) and dictate the choice of action of individuals, states, and corporations. For Verschueren (2012), the normative nature of ideological meaning is rarely questioned in a given society. However, it is possible to deconstruct ideologies especially when hegemony is at play, such as in the IDRS.

As ideologies are strongly held, even the non-native English speakers acknowledged that English as the lingua franca enables people with different native languages to communicate with each other and promotes mobility between countries. XW cited her own experience to illustrate how her proficiency in English enabled her to pursue a doctoral education in Canada and communicate with people from different countries. XL echoed this by writing "English as the lingua franca may facilitate the interaction between different languages and cultures, as well as the circulation of ideas, information and technology." This idea of using English as a communicative tool is also a strongly held ideology under the premise that we need to understand each other through a common language. One of the reasons that our two Chinese participants perceived English as necessary was 
also connected to the rise of English as a commodity in China; that is, the neoliberal transformation of China during the past three decades (Gao, 2017). Gao argued that the commodification of language has conditions which underpin actual practices of marketing language, such as socio-historical, political, and economic conditions.

For XL, doing international work means using English:

As a Chinese [citizen], when I was in China, I used to think highly about anything that has to do with "international" and to me that word mainly referred to "the West." Most of the Chinese people I worked with hold a similar attitude. In my $\mathrm{PhD}$ research, I did interviews with Chinese students in Alberta, and when they talked about the word "international", they all said that they would by default see that as "the West." That resonates with what I learned in my life experience in China. On the list of languages representing "the West", English may be on the top. That is why we would have it in mind by default that "international" events are supposed to be in English, and so international seminars are supposed to be in English. Otherwise it may seem to lack the taste of "international". That is from the perspectives of the host. Also, from the perspectives of the participants, we may be expecting an international seminar to be in English. Both parties may agree with one another on this point.

The domination of English and the prevalence of the idea that 'things are the way they are' demonstrated how ideology is at play, and there are practical reasons why we use one. Some languages seem 'easier' to use and more 'practical'. However, as Verschueren (2012: 12) mentioned, "when one is inclined to say 'but that is normal', that is a good chance that ideology is at work".

We need to keep in mind that all the non-native English speakers in this group developed fluency in speaking English, and thus are able to enjoy the benefits provided through this social 
capital (Bourdieu, 1986). For those who do not have the opportunity to learn English or to learn English as fluently, or those who have no interest in learning English, they are likely to be marginalized by this lack of ability. XL warned of the danger of "less tolerance about language diversity and cultural diversity" and "cultural hegemony since people from less developed areas may be given less opportunity to speak their minds under an international context due to language barriers." XL continued with: "Viewed from this perspective, more understanding and appreciation should be given to non-native English speakers on their efforts to communicative in English." We would like to add that the value of other languages might also be lost if we don't allow them to be used in the world.

Crystal (2003) mentioned that the challenge with global languages is that it might create a monolingual class unconcerned about learning other languages. In addition, there are also groups that lost their native languages because of this domination. In sum, as soon as the idea of English as a lingua franca comes in under the premise that we need a shared language, we eliminate other languages. Pennycook (2007) argued for the creation of alternative spaces of cultural and linguistic production instead of promoting the use of one particular language, which becomes hegemonic.

\section{Reflections on Language Use as a Result of the International Doctoral Seminar}

Before our departure, we did not think about language issues. There was an assumption that we would speak English in an international setting, and we were more concerned about how to act in a culturally appropriate and respectful way with our Chinese counterparts, since the seminar would be taking place in their country. The ideology that English is an international language and everyone would use it during the IDRS was prominent at that time. It is not until we were there in China with Mandarin speakers that we started to recognize that there were power issues related to the choice of language.

To answer the questions, "What did we realize about the privileging of a language as a result of IDRS?" and "what did we do about it?" we 
engaged in an exploration about our specific insights and experiences in the seminar. Blommaert (1999; 2005) and Kroskrity (2010) noted that language ideologies represent sets of beliefs found in discourses that are constructed by a specific social or cultural group for their own benefit. These ideologies are often difficult to comprehend and to grasp because they seem natural or logical. As XW mentioned, we only noticed it when we were in China:

I only noticed the issue of language use when I sat in the meeting room of BNU. I noticed that the BNU students were put at a disadvantageous position when they were surrounded by native English speakers. My experience of being an ESL speaker shows that in many cases, international conferences tend to have the assumption that people attending such conferences should be good enough with their English, otherwise they would not be there. The reality is that there is no other choice for ESL speakers if they do not attend international conferences in English.
As we mentioned earlier, we did not think about the use of language before we arrived in China, which demonstrated that the use of English is well spread, and it seems natural to use it everywhere. As JW mentioned in the following:

In reflection, I have been trying to think about what actions we could have taken to encourage the chinese students' participation and/or limit the shift of power to the English-speaking majority (i.e., the addition of the Canadian cohort to the Australian one). It is a very tough question that I feel uncomfortable answering without the input of the Chinese participants. Particularly, I worry about superficial solutions that merely placate my guilt for being part of the dominant group and having the unfair advantage of conversing easily with my colleagues.

JW included a very important suggestion in this comment as to invite Chinese participants to be part of the discussions regarding which languages to choose for the IDRS. JW seemed aware, likely from 
The Privileging of English Language Use in Academia: Critical Reflections from an International Doctoral Seminar

working with non-native speakers for years, of how those who speak English as a first language might feel guilty imposing their language.

Specifically, our reflections during the IDRS contributed to change in the dynamic of the seminar, as Chinese participants decided to meet to speak about issues of internationalization and language use in Mandarin. Guided by one of the faculty members from Australia who spoke Mandarin and one of our participants from Calgary, they took some time during the seminar to reflect, discuss, and plan a reflective position article on their own experiences. Our reflections in this article and theirs (Mu et al., 2019) demonstrated how both groups experienced the IDRS and the use of languages. There were nine native speakers of Chinese during the Seminar. As one participant mentioned: "Sometimes I noticed native English speakers were completely indulged in academic discussions in English. Of course, this is nothing wrong... But it inadvertently ignored Chinese participants and made them passive and silent. This is a phenomenon

of 'linguistic ignoring'... Nobody deliberately ignored us but we were in fact ignored" (Mu, 2018: 9).

From this last excerpt, we do see power at work (i.e., being ignored). Most of us understood that we needed to act upon language choices during the seminar in order to be inclusive of all participants. In other words, because we had experiences using languages and working with people from different languages, we were able to reflect on the domination of English during the seminar even if we did not think about it before the seminar. This allowed for reflection on English as a dominant language and as a subject of discussion from different perspectives. The suggestion that we had during the Seminar was to divide Mandarin speakers into their own group, so that they could use Mandarin instead of English. After recognizing and discussing how the English language was dominant, faculty members who spoke Mandarin, and Chinese students constituted a group to discuss the issue of the domination of English. 


\section{|Conclusion}

In this article we focused on sharing our reflections of an IDRS held in Beijing in 2015. Specifically, we noted the unacknowledged assumptions pre-departure that the IDRS would be conducted in English and how this privileging of English disproportionately benefited the native English-speaking participants. We also discussed how, upon acknowledging and engaging with this assumption, we were able to bring this forward to the larger group to help provide space for a trans-linguistic and cultural collaboration. Our experience is limited to one groups' perspective, which lacks the voices of the Australian and Chinese group. Despite this limitation, we sought to create greater equity in access to this partnership amongst all IDRS future participants. By sharing these reflections, we hoped to continue the discussion about linguistic and cultural equity in international collaborations and offer ideas about how to begin the process of creating space for alternative ways of being. Given the trend of increased globalization (Jacquemet, 2005; Stein \& de
Andreotti, 2016), continued exploration into trans-linguistic and -cultural practices is needed to expand these alternative ways of being to subvert the hegemony of English and support collaboration and diverse perspectives.

Transcultural flow involves the creation of meanings by blending different languages and cultures, which relies on people's acceptance of the free use of different languages and are always related to cultural aspects of the people that use those languages (Pennycook, 2007). Transcultural and translingual activities are able to reach a collaborative understanding between groups that want to work in an international setting (Fedoruk et al., 2018). For all of the $U$ of $C$ participants, the experience in Beijing and the reflections on the experience helped to enhance the transcultural perception in the sense of Welsch's (1999) "readjusting our inner compass: away from the concentration on the polarity of the own and foreign to an attentiveness for what might be common and connective wherever we encounter things foreign" ( $p$. 201). We were glad to see that we 
The Privileging of English Language Use in Academia: Critical Reflections from an International Doctoral Seminar Woodend, Fedoruk, Beek, Roy, Xuequin, Groen and Xiang

all demonstrated our awareness of the hegemonic position that English has in international exchanges and advocated for the use of other languages, or English varieties, to promote cultural diversity and equity of opportunity for all participants in the seminar. Our experiences offered an idea of how to pursue international work when participants do not speak the English standard and how to use the new space to build better collaborations where everyone is welcome.

Language issues and ideologies are not easy to point out, as they seem 'natural', but a reflective practice on how to achieve inclusivity and equality is possible. In a transcultural space, there is a need to shift assumptions about language use in academic forums to one where there will be discussion around how language will be used and navigated with all participants involved (Pennycook, 2007). All participants should have a voice in a mutual constructed space. In addition, if an international academic forum is in English, all participants should discuss how to distribute responsibility and burden for creating access for those attending, and the decisions should be made by all participants. For future directions, continued collaboration and reflection with non-English speaking or English as an additional language academics about roles and responsibilities in addressing this inequity is needed to enhance equity.

\section{End notes}

1 Correspondence concerning this article should be sent to Dr. Sylvie Roy, University of Calgary, Werklund School of Education, 2500 University Dr. NW EDT 346, Calgary, Alberta, Canada T2N1N4, syroy@ucalgary.ca 


\section{|References}

Ahn, H. (2014). Teachers' attitudes towards Korean English in South Korea. World Englishes, 33, 195-222.

Fedoruk, L., Woodend, J., Groen, J., Beek, A., Roy, S., Wu, X., \& Li, X. (2018). Critical reflections in international contexts: PolyEthnographic accounts of an international doctoral research seminar. The Qualitative Report, 23, 1256-1269.

Bhabha, H. (1994). The location of culture. London, England: Routledge.

Blommaert, J. (2005). Discourse. A critical introduction. Cambridge, England: Cambridge University Press.

Blommaert, J. (Ed.) (1999). Language ideological debates. Berlin, Germany: Walter de Gruyter.

Bourdieu, P. (1986). The forms of capital. In J. G. Richardson (Ed.), Handbook of theory and research for the sociology of education (pp. 241-258). New York, NY: Greenwood.

Chang, B-M. (2011). The roles of English language education in Asian context. Journal of Pan-Pacific Association of Applied Linguistics, 15, 191-206.

Cohen, L., L. Manion \& K. Morrison. (2018). Research Methods in Education. London, New York: Routledge. 8th edition.

Crystal (2003). English as a global language. Cambridge, England: Cambridge University.

Gee, J. P. (2004). New times and new literacies: Themes for a changing world. In S. Warshauer Freedman \& A. F. Ball. (Eds). Bakhtinian perspectives on language, literacy, and learning (pp. 279-306). Cambridge, England: Cambridge University Press.

Gil, J. (2011). A comparison of the global status of English and Chinese: Towards a new global language? English Today 27, 52-9. 
The Privileging of English Language Use in Academia: Critical Reflections from an International Doctoral Seminar

Graddol, D. (1997). The future of English? London, England: British Council. Retrieved from http://www.britishcouncil.org/learning-elt-future.pdf

Guo, S., \& Guo, Y. (Eds.) (2016). Spotlight on China: Changes in education under China's market economy. Rotterdam, Netherlands: Sense Publishers.

Guo, Y. (2012). Teaching English for economic competitiveness: Emerging issues and challenges in English education in China. Canadian and International Education, 41, 28-50.

He, D., \& Li, D. (2009). Language attitudes and linguistic features in the "China English” debate. World Englishes, 28, 70-89.

Jacquemet, M. (2005). Transidiomatic practices: Language and power in the age of globalization. Language and communication, 25, 257-277.

Kachru, B. (1997), World Englishes and English-using communities. Annual Review of Applied Linguistics, 17, 66-87.

Kramsch, C. (1999). Global and local identities in the contact zone. In C. Gnutzmann (Ed.). Teaching and learning English as a global language: Native and non-native perspectives (pp. 131-143). Tüumbingen, Germany: Stauffenburg Verlag.

Kroskrity, P. V. (2010). Language ideologies. Evolving perspectives. In J. Jaspers, J.O. Ostman \& J. Werschueren (Eds), Society and language use (pp. 192211). Amsterdam, NetherlandsL: John Benjamins Publishing Company.

Levis, J., Sonsaat, S., \& Link, S. (2017). Students' beliefs about native vs. non-native pronunciation teachers. In de Dios Martinez Aguda J. (Ed.), Native and nonnative teachers in English language classrooms: Professional challenges and teacher education (pp. 205-238). Boston, MA: De Gruyter Mouton.

Luke, A. (2008). Using Bourdieu to make policy: Mobilizing community capital and literacy. In J. Albright \& A. Luke (Eds.) Pierre Bourdieu and literacy education (pp. 347-362). New York, NY: Routledge. 
Merriam, S. B., \& Tisdell, E. J. (2016). Qualitative research: A guide to design and implementation. San Francisco, CA: Jossey-Bass.

$\mathrm{Mu}, \mathrm{G} . \mathrm{M}$. (2018). Linguistic field in an international doctoral workshop: Sociological implications for doctoral pedagogy. Paper presented at the Symposium of Asia-Pacific Talent and Knowledge Mobilities Calgary, Canada, 11 October.

Mu, G. M., Liu, L. L., Fu, W., Hao, D., Jia, N., Qin, Y., Wu, X. (2019). Using English at an international doctoral workshop: A three-level field analysis. In G. M. $\mathrm{Mu}, \mathrm{K}$. Dooley, \& A. Luke (Eds.), Bourdieu and Chinese education: Inequality, competition, and change (pp. 192- 213). New York: Routledge.

Mu, G. M., Zhang, H., Cheng, W., Fang, Y., Li, S, Wang, X., \& Dooley, K. (2019). Negotiating scholarly identity through an international doctoral workshop: A cosmopolitan approach to doctoral education, Journal of Studies in International Education, 23, 139-153.

Pennycook, A. (2007). Global Englishes and transcultural flow. London, England: Routledge.

Phillipson, R. (2009). Linguistic imperialism continued. Hyderabad, India: Orient Blackswan Private Limited.

Rallis, S. F., \& Rossman, G. B. (2003). Learning in the field: An introduction to qualitative research. Thousand Oaks, CA: SAGE

Stein, S. \& de Andreotti, V.O. (2016). Cash, competition, or charity: International students and the global imaginary. Higher Education, 72, 225-239.

Verschueren, J. (2012). Ideology in language use: Pragmatic guidelines for empirical research. Cambridge, England: Cambridge University Press.

Welsch, W. (1999). Transculturality: The puzzling form of cultures today. In M. Featherstone \& S. Lash (Eds.), Spaces of culture: City, nation, world (pp. 192213). London, England: Sage. 